\title{
Factors associated with medication adherence among heart failure patients and their caregivers
}

\author{
Brooke Aggarwal, Ashley Pender, Lori Mosca, Heidi Mochari-Greenberger * \\ Department of Medicine, Columbia University Medical Center/New York-Presbyterian Hospital, New York, United States
}

Received: September 10, 2014

Accepted: November 9, 2014 Online Published: December 10, 2014

DOI: $10.5430 /$ jnep.v5n3p22

URL: http://dx.doi.org/10.5430/jnep.v5n3p22

\begin{abstract}
Background: Reducing the rate of rehospitalization among heart failure patients is a major public health challenge; medication non-adherence is a crucial factor shown to trigger rehospitalizations. Objective: To collect pilot data to inform the design of educational interventions targeted to heart failure patients and their caregivers to improve medication adherence.

Methods: Heart failure patients with an implantable cardioverter defibrillator and their family caregivers were recruited from an outpatient electrophysiology clinic at an urban university medical center $(\mathrm{N}=10$ caregiver and patient dyads, $70 \%$ race/ethnic minority, mean patient age $=63$ years). Quantitative and qualitative research methods were utilized. Semi-structured individual interviews were conducted to assess patients' and caregivers' individual interest in, and access to, new medication adherence technologies. Patient adherence to medications, medication self-efficacy, and depression were assessed by validated questionnaires. Medication adherence and hospitalization rates were assessed among patients at 30-days post-clinic visit by mailed survey.
\end{abstract}

Results: At baseline, $60 \%$ of patients reported sometimes forgetting to take their medications. The most common factors associated with non-adherence included forgetfulness (50\%), having other medications to take (20\%), and being symptom-free (20\%). At 30-day follow-up, half of patients reported non-adherence to their medications, and 1 in 10 reported being hospitalized within the past month. Dyads reported widespread access to technology, with the majority of dyads showing interest in mobile applications and text messaging. There was less acceptance of medication-dispensing technologies; caregivers and patients were concerned about added burden.

Conclusions: The majority of etiologies of medication non-adherence were subject to intervention. Enthusiasm from patients and caregivers in new technologies to aid in adherence was tempered by potential burden, and should be considered when designing interventions to promote adherence.

Key Words: Heart failure, Caregiving, Adherence, Nursing education

\section{Introduction}

Heart failure is one of the most common cardiac diagnoses among individuals 65 years and older, with over 1 million hospitalizations for heart failure each year in the U.S. alone, at an estimated cost of $\$ 29$ billion dollars. ${ }^{[1]}$ Medication adherence has recently been shown to be the strongest predictor of hospitalization among heart failure patients. ${ }^{[2]}$

Optimal adherence to medications, and thus better management of heart failure, is especially important for heart failure patients who also have implantable cardioverter defib-

\footnotetext{
*Correspondence: Heidi Mochari-Greenberger; Email: hm2028@columbia.edu; Address: Department of Medicine, Columbia University Medical Center/New York-Presbyterian Hospital, New York, United States.
} 
rillators (ICD)s. The majority of hospitalizations for ICD patients are caused by multiple appropriate shock interventions, ${ }^{[3]}$ many times in the setting of worsening heart failure. Reducing the occurrence of ICD shocks could potentially lead to decreased rates of rehospitalization and/or death in heart failure patients. ${ }^{[4,5]}$ One of the first-line approaches recommended for reduction of shocks is the use of antiarrhythmic medications or beta-blockers. ${ }^{[6]}$ However, optimal adherence to beta blockers is reached in only $47 \%-57 \%$ of heart failure patients. ${ }^{[7]}$

A potential low-cost novel strategy to reduce heart failure hospitalization rates is to target education for heart failure patients and their informal caregivers to increase adherence to medical recommendations, including adherence to medications. In a hospital-based study we demonstrated that the majority of hospitalized cardiac patients had access to a caregiver, ${ }^{[8]}$ and that caregiving was linked to greater medication adherence. ${ }^{[9]}$ However, patients with informal caregivers compared to those without were sicker and more likely to be rehospitalized, suggesting they may be a key population to target with evidence-based interventions to improve outcomes. ${ }^{[10]}$

In this study, we sought to explore factors that may affect adherence to medications among heart failure patients with an ICD and their caregivers, an understudied population. The objective of this study was to collect pilot data to inform the design of family-based educational interventions to improve medication adherence among patients with heart failure.

\section{Methods}

\subsection{Study design}

This was a qualitative and quantitative pilot study conducted among heart failure patients and their informal caregivers. Patient and caregiver participants were recruited from the outpatient electrophysiology clinic at Columbia University Medical Center/New York Presbyterian Hospital, and were enrolled between March 2013 and May 2013. Participants completed a baseline assessment and interview composed of semi-structured interviews and standardized questionnaires during the baseline visit, and a standardized mailed questionnaire at 30-days. Follow up at 30-days was $100 \%$.

\subsection{Study participants}

The study population comprised New York Heart Association (NYHA) class II-III heart failure patients with ICDs, and informal caregivers designated by the patients $(n=10$ dyads). Each dyad consisted of one caregiver and one patient. Informal caregivers were defined as a family member, spouse or friend who assisted with daily activities and medical care for the patient without receiving compensation. Patient and/or caregiver participants were excluded if they were unable to complete the interview and/or sur-

Published by Sciedu Press veys, or if they did not speak English or Spanish. All patient and caregiver participants were required to give written informed consent. The study was approved by the Institutional Review board of Columbia University Medical Center.

\subsection{Baseline qualitative assessments}

Both patient and caregiver participants completed semistructured qualitative interviews on their experiences with, and willingness to use medication adherence technology. The qualitative method of study was chosen in order to elicit first-hand descriptive data from participants, in their own words. Barriers to medication adherence and feasibility of potential interventions were assessed via interviews conducted by a bilingual (English/Spanish) research assistant interviewer trained in qualitative methodology.

Participants were interviewed together as a dyad (caregiver and patient). They were asked to speak about their interests and preferences for potential technology designed to increase medication adherence. Total duration of the interviews was approximately 60 minutes each. Interviews were audio taped using an electronic tape recorder and subsequently transcribed. A sample question was, "Would you be interested in using innovative technologies such as text messaging and mobile applications?" Additional probing questions and appropriate prompts (e.g., "tell me more") were used as appropriate.

\subsection{Baseline quantitative assessments}

Patient participants completed standardized, validated questionnaires at baseline regarding demographics, medication adherence, medication self-efficacy, and depressive symptoms.

Medication adherence was assessed by the Morisky Medication scale. ${ }^{[11]}$ The Morisky Medication scale is a four question self-report assessment for measuring adherence to medication regimen, based on the theory that lapse in medication taking is attributable to a combination of forgetfulness, careless behavior, medication cessation with symptom relief or adverse symptoms with medication taking. A sample question is, "Do you ever forget to take your medicine?" Answers are scored as yes or no. The number of "yes" responses are then tabulated on a scale ranging from 0 (high adherence) to 4 (low adherence). This instrument has high reliability $(\alpha=.61)$, internal consistency predictive validity and concurrent validity.

Medication self-efficacy was assessed by the Medication Adherence Self Efficacy Scale (MASES-R). ${ }^{[12]}$ It is a 13item questionnaire that assesses patient's opinion of their ability to adhere to their medication regimen in certain situations $(\alpha=.91)$. A sample situation is, "when you are busy at home". Scoring is based on response with 4 points for a response of "extremely sure" and 1 point for a response of "not at all sure". 
Depressive symptoms were assessed by the Beck Depression Inventory, second edition (BDI-II). ${ }^{[13]}$ This 21 item self-report instrument allows for a quantitative assessment of depression over a 2-week period that is concordant with criteria for depression as detailed in DSM IV. Each item is scored on a four-point scale and total scores correspond to minimal depression (0-13 points), mild depression (14-19 points), moderate depression (20-28 points), and severe depression ( $>29$ points). This instrument has been shown to have good validity and reliability $(\alpha=.86)$.

\subsection{Thirty-Day follow-up assessments}

A brief 1-page questionnaire was mailed to patient participants at 30-days to assess medication adherence and hospital admissions that took place within the previous month.

\subsection{Qualitative analysis}

Data derived from the qualitative portion of this study was analyzed by conventional content analysis, which is appropriate when there is limited research in a specific area. ${ }^{[14]}$ The criteria established by Lincoln and Guba including credibility, dependability, confirmability and transferability were used to ascertain the trustworthiness of this qualitative research. ${ }^{[15,16]}$ Methodology triangulation was employed through the use of interviews, questionnaires, as well as observations of the participants during the interviews.

Qualitative interview recordings were transcribed verbatim. Categories or themes were established based on the available literature and a conceptual framework was established. The established framework included the following categories: 1) technology experience, 2) challenges, 3) usability and interest, and 4) medication adherence experience. Observations regarding patient and caregiver participant responses on their interest and preferences for medication adherence technology were synthesized and systematically coded according to themes that emerged from the data. Under the category of technology experience, subcategories included reactions/feelings, and perceptions. The challenges category included subcategories of physical challenges and mental challenges. The usability and interest category included subcategories of implementation and likelihood of use. The medication adherence experience category was divided into subcategories of cost and reminders. Transcripts were read and coded using the established codebook until saturation of themes was reached.

\subsection{Quantitative analysis}

Quantitative analyses were performed using SAS statistical software (version 9.2, Cary NC). Continuous variables were described using means, and categorical variables were described using frequencies. The association between depressive symptoms and medication non-adherence was evaluated using logistic regression.

\section{Results}

\subsection{Participant characteristics}

The characteristics of the participants are presented in Table 1. Patients were older than their caregivers. Nine out of 10 caregivers were female. Twice as many caregivers were college educated compared to patients. Over half of the caregivers were the patient's spouse/partner.

Table 1: Characteristics of study participants $(\mathrm{N}=20)$

\begin{tabular}{lll}
\hline \multirow{2}{*}{ Characteristic } & $\begin{array}{l}\text { Caregivers } \\
(\mathbf{n}=\mathbf{1 0})\end{array}$ & $\begin{array}{l}\text { Patients } \\
(\mathbf{n}=\mathbf{1 0})\end{array}$ \\
\cline { 2 - 3 } & $\mathrm{N}(\%)$ & $\mathrm{N}(\%)$ \\
\hline Age in Years (Mean \pm SD) & $53 \pm 17$ & $63 \pm 20$ \\
$\begin{array}{l}\text { Female vs. Male } \\
\text { Married vs. Single/Divorced/ }\end{array}$ & $9(90)$ & $6(60)$ \\
$\begin{array}{l}\text { Separated } \\
\text { Education }(\geq \text { college vs. }<\text { college) }\end{array}$ & $7(70)$ & $6(60)$ \\
Race/Ethnicity: & $6(60)$ & $3(30)$ \\
$\quad \begin{array}{l}\text { Caucasian } \\
\text { Black }\end{array}$ & $3(30)$ & $3(30)$ \\
$\quad \begin{array}{l}\text { Hispanic } \\
\text { Other }\end{array}$ & $3(30)$ & $2(20)$ \\
\hline & $3(30)$ & $3(30)$ \\
& $1(10)$ & $2(20)$ \\
\hline
\end{tabular}

\subsection{Medication adherence}

Six out of 10 patients reported sometimes forgetting to take their medications according to Morisky Medication scale. The most common situations that made it difficult for patients to remember taking their medications as prescribed included "when they are busy at home" (30\%), "when they are in a public place" (20\%), "when they have other medications to take" (20\%), and "when they feel well" (20\%), as measured by the MASES-R.

In semi-structured interviews on the topic of medication adherence technologies, the overwhelming majority of patients and caregivers reported having access to the internet (80\%) and owning a cell phone $(70 \%)$, particularly smart phones with internet capability $(60 \%)$. Half of patients and caregivers reported being interested in using innovative technologies such as text messaging and mobile applications to assist with their daily healthcare needs. However, $80 \%$ of caregivers and $40 \%$ of patients reported that they would not be likely to use technologies such as medication dispensing machines, Glow-cap medication reminders, and text message reminders if they were available at a small cost.

Patient and caregiver qualitative feedback regarding the use of technology to improve medication adherence is presented in Table 2. In general, patients were open to trying new technologies to assist with medication adherence, provided that someone showed them how to use it and gave a through explanation of the device(s). Potential challenges mentioned by patients included the possibility of not hearing an alarm 
or reminder bell on a device, or what would happen if the device stops working properly. Some caregivers expressed concerns about potential additional burden that new technologies may confer. The majority of patients said that they were likely to use new technology to improve their adherence to medications, or at least try it, depending on the specific costs and benefits to them.

Table 2: Quotes from patients and caregivers regarding medication adherence technologies

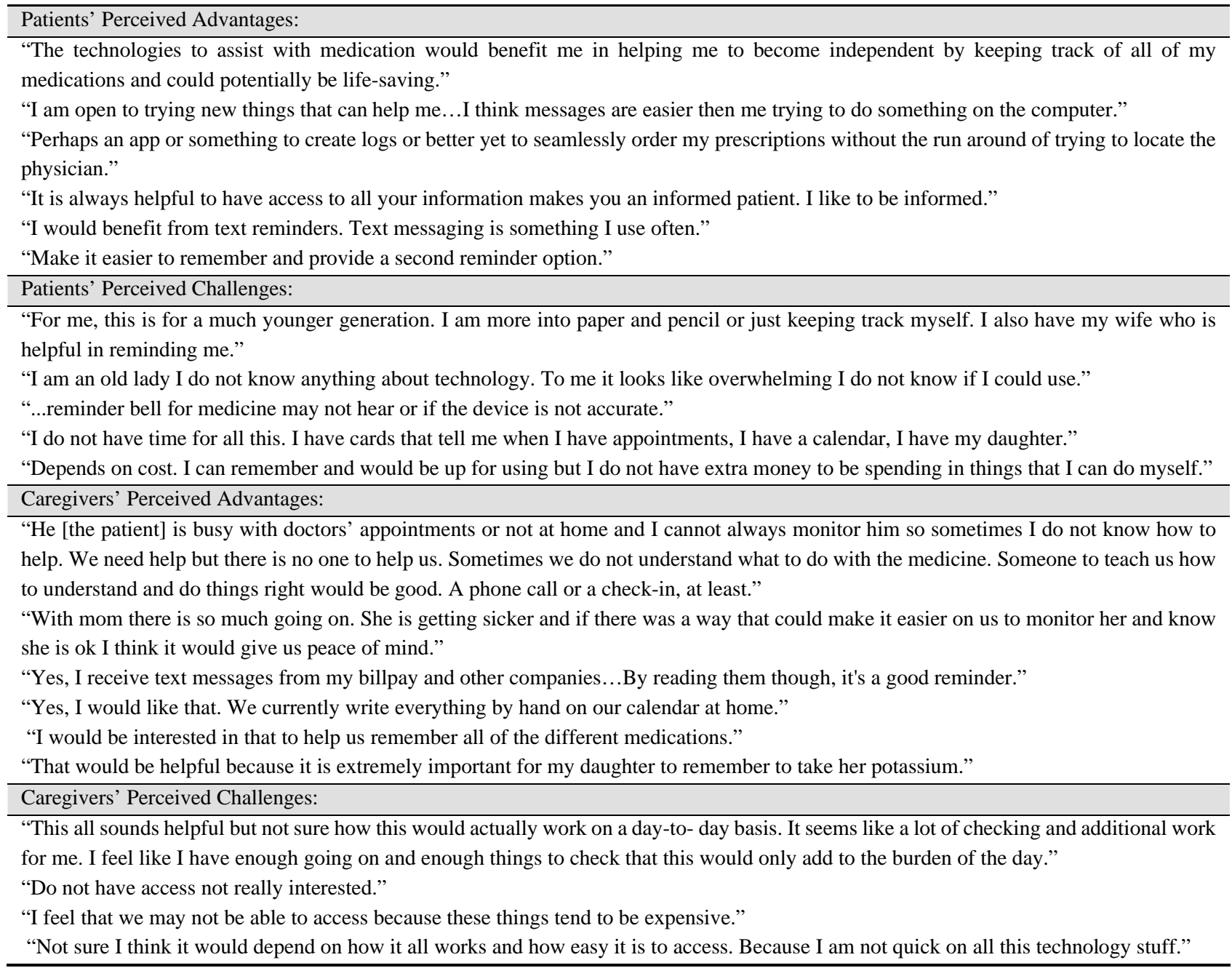

\subsection{Depressive symptoms}

Patient Beck Depression Inventory score ranged from zero to 19 points, with a mean score of 8.3 points. Ten percent of participants were classified as mildly depressed at baseline, as measured by the Beck Depression Inventory.

\subsection{Medication non-adherence and hospitalization at 30-Days}

At 30-day follow-up, 1 out of 10 patients reported being readmitted to the hospital within the past month, and half of patients reported non-adherence to their medications (missing one or more pills/doses per week, on average). There was a trend for significantly higher baseline depression scores among patients who were non-adherent to their medications at 30-days versus those who were adherent at 30-days (mean Beck Depression Inventory score of 11.6 vs. $5.0, p=.07)$.

\section{Discussion}

Several important findings from this study can inform the development of educational interventions for heart failure patients and their caregivers, designed to improve medication adherence. More than half of patients reported nonadherence to their medications and the most common barriers to adherence identified in both quantitative and qualitative approaches were forgetting to take their medications due to distractions in daily life, being away from home, having more than one medication to take, and feeling well enough not to take it. Potential mechanisms to increase adherence that were acceptable were mobile applications, au- 
tomated check-ins, and text message medication reminders. Patient-caregiver dyads reported widespread access to technology including smart phones, suggesting potential modes for improving adherence. There was less acceptance of medication-dispensing technologies, as the majority of caregivers (and a few of the patients) were concerned about additional burden to their already cumbersome medical regimens. The concerns expressed by the participants in this study are similar to those in previous studies of the experiences of heart failure patients. ${ }^{[17]}$

Our findings related to reasons for non-adherence are consistent with prior research. ${ }^{[18-20]}$ Ho, Bryson, and Rumsfeld (2009) used five major groupings to characterize the etiology of non-adherence as related to the "health system", "socio-economic factors", "condition", "patient", or "therapy" which supports a general trend in the literature towards a multifactorial explanation of non-adherence. ${ }^{[20]}$ The majority of etiologies of non-adherence identified in our study of heart failure patients with ICDs can be grouped into the latter three categories, and are thus amenable to behavioral intervention. This indicates that a tailored intervention might help to mitigate the "condition", "patient" and "therapy" aspects of non-adherence and respectively, cue the patient to take medication when symptoms are not present, encourage medication-taking behavior, and help the patient navigate potentially complex medical regimens. ${ }^{[20]}$ The added challenge for clinicians in developing such interventions will lie in fulfilling these needs without introducing additional burden, which was an important concern identified by participants.

In our study, we also noted a higher incidence of depression based on the BDI-II among patients who were nonadherent to medications. The association between depression and medication non-adherence has been documented previously. ${ }^{[21,22]}$ However few studies have examined this relationship in heart failure patients. While our study did not formally test for causal relation between depression and non-adherence, the data suggest that identifying patients who are depressed may help to detect those at risk for nonadherence.
The strengths of this study include the mix of qualitative and quantitative methodology in a diverse, high-risk population. This study has limitations that should be considered. First, this study had a relatively small sample size and the patients were limited to NYHA class II and III. Thus, the findings may be less generalizable to a general population of heart failure patients with ICDs and their informal caregivers. Medication adherence was ascertained by selfreport, as opposed to more objective measures such as electronic medication measuring or direct observation. However, the Morisky Medication Scale is validated and predictive of cardiovascular-associated medication taking behavior. ${ }^{[11]}$

\section{Conclusion}

In conclusion, this study provides important insight into the experiences of heart failure patients with an ICD and their informal caregivers that may be used to inform the design of interventions aimed to improve medication adherence. Non-adherence to medications in heart failure patients contributes to a substantial burden on the healthcare system. The majority of etiologies of medication non-adherence identified in this study were subject to intervention. These data indicate that patients and their caregivers are receptive to new technologies aimed to improve adherence. This enthusiasm from patients and caregivers was tempered by potential burden, and should be considered when designing interventions to promote adherence.

\section{Acknowledgements}

Dr. Brooke Aggarwal received grant support for this study through the National Center for Advancing Translational Sciences, National Institutes of Health (UL1 TR000040). Dr. Lori Mosca and Dr. Heidi Mochari-Greenberger received grant support through the National Heart, Lung, \& Blood Institute (K24 HL076346).

\section{Conflicts of Interest Disclosure}

The authors have no competing interests/conflict of interests to report.

\section{References}

[1] Joynt KE, Orav EJ, Jha AK. The association between hospital volume and processes, outcomes, and costs of care for congestive heart failure. Ann Intern Med. 2011 Jan 18; 154(2): 94 102. PMid:21242366 http://dx.doi.org/10.7326/0003-481 9-154-2-201101180-00008

[2] Riegel B, Knafl GJ. Electronically monitored medication adherence predicts hospitalization in heart failure patients. Patient Prefer Adherence. 2013 Dec 5; 8: 1-13. PMid:24353407 http://dx.doi.o rg/10.2147/PPA.S54520
[3] Korte T, Jung W, Ostermann G, Wolpert C, Spehl S, Esmailzadeh B, Lüderitz B. Hospital readmission after transvenous cardioverter/defibrillator implantation; a single centre study. Eur Heart J. 2000 Jul; 21(14): 1186-1191. PMid:10924302 http:// dx.doi.org/10.1053/euhj.1999. 2044

[4] Larsen GK, Evans J, Lambert WE, Chen Y, Raitt M. Shocks burden and increased mortality in implantable cardioverter-defibrillator patients. Heart Rhythm. 2011; 8(12): 1881-1886. PMid:21816127 http://dx.doi.org/10.1016/j.hrthm.2011.07.036

[5] Pedersen SS, van den Broek KC, Theuns DAMJ, et al. Risk of chronic anxiety in implantable defibrillator patients: a multi-center study. Int J Cardiol 2009. 
[6] Gehi AK, Mehta D, Gomes JA. Evaluation and management of patients after implantable cardioverter-defibrillator shock. JAMA. 2006 Dec 20; 296(23): 2839-2847. PMid:17179461 http://dx.d oi.org/10.1001/jama.296.23.2839

[7] Setoguchi S, Choudhry NK, Levin R, Shrank WH, Winkelmayer WC. Temporal trends in adherence to cardiovascular medications in elderly patients after hospitalization for heart failure. Clin Pharmacol Ther. 2010 Oct; 88(4): 548-554. PMid:20827266 http: //dx.doi.org/10.1038/clpt.2010.139

[8] Mosca L, Mochari-Greenberger H, Aggarwal B, Liao M, SueroTejeda N, Comellas M, Rehm L, Umann TM, Mehran R. Patterns of caregiving among patients hospitalized with cardiovascular disease. J Cardiovasc Nurs. 2011 Jul-Aug; 26(4): 305-311. PMid:21330929 http://dx.doi.org/10.1097/JCN.0b013e3181f34bb3

[9] Aggarwal B, Comellas M, Liao M, Mosca L. Medication adherence is Associated with Having a Caregiver among Cardiac Patients. Ann Behav Med. 2013; 46: 237-242. PMid:23536121 http: //dx.doi.org/10.1007/s12160-013-9492-8

[10] Mosca L, Aggarwal B, Mochari-Greenberger H, Liao M, Blair J, Cheng B, Comellas M, Rehm L, Suero-Tejeda N, Umann T. Association Between Having a Caregiver and Clinical Outcomes 1 Year After Hospitalization for Cardiovascular Disease. Am J Cardiol. 2012; 109(1): 135-139. PMid:21962999 http://dx.doi.org/10.1016 /j.amjcard.2011.07.072

[11] Morisky DE, Green LE, Levine DM. Concurrent and predictive validity of a self-reported measure of medication adherence. Med Care. 1986; 24(1): 67-74. http://dx.doi.org/10.1097/00005 650-198601000-00007

[12] Fernandez S, Chaplin W, Schoenthaler AM, Ogedegbe G. Revision and validation of the medication adherence self-efficacy scale (MASES) in hypertensive African Americans. J Behav Med. 2008; 31(6): 453-462. PMid:18784996 http://dx.doi.org/10.1007 /s10865-008-9170-7

[13] Beck AT, Ward CH, Mendelson M, Mock J, Erbaugh J. An inventory for measuring depression. Arch Gen Psychiatry. 1961; 4(6): 561571. http://dx.doi.org/10.1001/archpsyc.1961.0171012 0031004
[14] Hsieh-Fang H, Shannon S. Three approaches to qualitative content analysis. Qualitative Health Research. 2005; 15: 12771288. PMid:16204405 http://dx.doi.org/10.1177/1049732 305276687

[15] Lincoln Y, Guba EG. Naturalistic Inquiry. London: Sage, 1985.

[16] Polit D, Beck C. Nursing Research: Generating and Assessing Evidence for Nursing Practice, 8th ed. New York: Wolters Kluwer Health/Lippincott, Williams \& Wilkins, 2008.

[17] Scotto, CJ. The lived experience of adherence for patients with heart failure. J Cardiopulm Rehabil. 2005; 25(3): 158-163. PMid:15931019 http://dx.doi.org/10.1097/00008483-200 505000-00006

[18] Osterberg L, Blaschke T. Adherence to medication. N Engl J Med. 2005; 353(5): 487-97. PMid:16079372 http://dx.doi.org/10. 1056/NEJMra050100

[19] Vrijens B, Vincze G, Kristanto P, Urquhart J, Burnier M. Adherence to prescribed antihypertensive drug treatments: longitudinal study of electronically compiled dosing histories. BMJ. 2008; 336(7653): 1114-1117. PMid:18480115 http://dx.doi.org/10.1136/bmj .39553 .670231 .25

[20] Ho PM, Bryson CL, Rumsfeld JS. Medication adherence: its importance in cardiovascular outcomes. Circulation. 2009; 119(23): 3028-3035. PMid:19528344 http://dx.doi.org/10.1161/CIR CULATIONAHA. 108.768986

[21] DiMatteo MR, Lepper HS, Croghan TW. Depression is a risk factor for noncompliance with medical treatment meta-analysis of the effects of anxiety and depression on patient adherence. Arch Intern Med. 2000; 160(14): 2101-2107. http://dx.doi.org/10.1001 /archinte.160.14.2101

[22] Bauer LK, Caro MA, Beach SR, Mastromauro CA, Lenihan E, Januzzi JL, Huffman JC. Effects of depression and anxiety improvement on adherence to medication and health behaviors in recently hospitalized cardiac patients. Am J Cardiol. 2012; 109(9): 12661271. PMid:22325974 http://dx.doi.org/10.1016/j.amjca rd. 2011.12 .017 